\title{
Multicystic Mesothelioma
}

National Cancer Institute

\section{Source}

National Cancer Institute. Multicystic Mesothelioma. NCI Thesaurus. Code C3765.

An intermediate grade neoplasm arising from mesothelial cells. It occurs in the peritoneum, extraperitoneal space, omentum, or pelvic or abdominal viscera. It is characterized by the presence of multiple cysts lined by flattened or cuboidal mesothelial cells. There is no evidence of significant cytologic atypia or increased mitotic activity. It usually occurs in young to middle-aged women. Patients present with abdominal or pelvic mass and pain. Approximately half of the cases recur. The recurrences may appear several years after the initial diagnosis. Rare cases of transformation to malignant mesothelioma have also been described. 